\title{
Influence of the Amount of Steel Fibers on Fracture Energy and Drying Shrinkage of HPFRCC
}

\author{
Weina Guo $\mathbb{D}^{1},{ }^{1}$ Peng Zhang $\mathbb{D}^{1},{ }^{1}$ Yupeng Tian, ${ }^{1}$ Bing Wang, ${ }^{2}$ and Wan $\mathrm{Ma}^{1}$ \\ ${ }^{1}$ Center for Durability \& Sustainability Studies of Shandong Province, Qingdao University of Technology, Qingdao 266033, China \\ ${ }^{2}$ Qingdao Municipal Construction Group, Qingdao 266000, China \\ Correspondence should be addressed to Peng Zhang; peng.zhang@qut.edu.cn
}

Received 26 February 2020; Revised 30 May 2020; Accepted 1 June 2020; Published 20 June 2020

Guest Editor: Rishi Gupta

Copyright (c) 2020 Weina Guo et al. This is an open access article distributed under the Creative Commons Attribution License, which permits unrestricted use, distribution, and reproduction in any medium, provided the original work is properly cited.

The fracture energy of the high-performance fiber-reinforced cement-based composite (HPFRCC) can be modified within wide limits by the variation of the amount of steel fibers added to the fresh mix. First of all, considering the actual engineering conditions in Qingdao, the materials commonly used in Qingdao were selected. The optimal reference mix proportion of the HPFRCC cementing material was proposed through determination of fluidity and flexural strength. Based on the optimal mix proportion, the uniaxial tensile, fracture, and dry shrinkage properties of HPFRCC with different steel fibers are systematically studied. Stress-strain diagrams of the different samples were measured under the uniaxial tensile test, wedge splitting test, and three-point bending test. The steel fiber content was varied between 0 and $200 \mathrm{~kg} / \mathrm{m}^{3}$. The load bearing capacity and the fracture energy were determined experimentally. In addition, moisture loss as a function of time and shrinkage was determined in an environment of $20^{\circ} \mathrm{C}$ and $50 \% \mathrm{RH}$ (relative humidity). The results indicate that the maximum load increases significantly in the HPFRCC series reinforced by 150 and $200 \mathrm{~kg} / \mathrm{m}^{3}$ of steel fibers. Both have a hardening branch developed after the first crack deflection due to the high percentage of fibers bridging the crack surfaces. The load bearing capacity and fracture energy increased almost linearly with the steel fiber content. It was found that the three-point bending test is more applicable in measuring the fracture energy of HPFRCC than the wedge splitting test. The addition of steel fibers decreased the moisture diffusion and consequently the drying shrinkage of HPFRCC, and there was minimum weight loss and deformation when the steel fiber content was $150 \mathrm{~kg} / \mathrm{m}^{3}$. The results obtained will be presented and discussed.

\section{Introduction}

Concrete is the most widely used building material, but its brittleness increases with its strength. Adding fiber into concrete can effectively improve the brittleness of concrete and improve its own crack resistance. At present, the fibers often added in the cement matrix are mainly steel fibers, glass fibers, synthetic fibers, natural fibers, and so on, and among them, the steel fiber is the most widely used [1-11]. The related research results show that the addition of the steel fiber into the cement matrix can greatly improve the fracture toughness and fracture energy of concrete [12-16]. To further improve the compactness and mechanical properties of concrete, in addition to adding steel fibers, fine pozzolanic reaction additives such as fly ash and silica fumes are also added [17-28]. Due to the pozzolanic reaction and filling, the composite further achieves a more compact structure, which is called HPFRCC [29-32]. Because of its compact structure, it has high strength, high durability, low porosity, and good volume stability [29, 33-37]. HPFRCC is a new type of cementitious material which appeared in the mid-1990s [38]. It has the characteristics of low water-binder ratio, superhigh molding, and so on $[39,40]$. Compared to the ordinary concrete, HPFRCC has a very high compressive strength of 100-800 MPa, tensile strength of 20-50 MPa, elastic modulus of 50-60 GPa, and fracture energy up to $40 \mathrm{~kJ} / \mathrm{m}^{2}$ [41-44]. At present, HPFRCC is the most prospective construction material for both civil and military structures, such as for nuclear waste storage, containment, fortification, highway bridge, and municipal and high-rise buildings [39, 45-49].

At home and abroad, the mechanical properties, durability, volume stability, microstructure, and preparation 
technology of HPFRCC have been studied extensively [50-55]. There are also many research studies on the fracture energy of HPFRCC. Sovják et al. [56] studied the relationship between the effective fracture energy and the strain rate of HPFRCC with different steel fiber volume contents and concluded that the higher the fiber volume content, the lower the strain rate sensitivity. Nguyen et al. [57] studied the effect of different types of steel fibers on the fracture energy of steel fiber-reinforced concrete, and the results showed that the ratio of elastic fracture energy to total fracture energy was the lowest, ranging from 0.02 to 0.08 , and the local fracture energy and total fracture energy was the highest, ranging from 0.38 to 0.82 . Ren et al. [39] studied the influence of different steel fiber contents and types on the fracture energy and fracture toughness of ultrahigh-performance cement-based composites. The results showed that the steel fiber contents and types had a great influence on the fracture toughness and fracture energy. Tran et al. [6] analyzed the fracture energy of UHPFRC at a strain rate of $5-92 \mathrm{~s}^{-1}$ and obtained a specimen with a fiber content of $1-1.5 \%$ with a very high fracture energy $\left(28-71 \mathrm{~kJ} / \mathrm{m}^{2}\right)$. In the above literature, the influence of different types of steel fibers on the fracture performance of HPFRCC was mainly studied. While the targeted research on the change of steel fiber content in HPFRCC from its fracture energy and dry shrinkage is relatively less, they are essential to improve the service performance of the structure and the collapse resistance of the structure under extreme load or environments, especially.

To fully understand the influence of different steel fiber content on the fracture and dry shrinkage properties of HPFRCC, this paper first uses Qingdao local materials as the base material and obtains the best mix proportion of the matrix materials through the fluidity and flexural strength test; then, the steel fiber is added on the basis of this best mix proportion and is made into the HPFRCC studied in this paper. Firstly, the fracture energy of HPFRCC with different contents of steel fiber is studied and analyzed by using the wedge splitting method and the three-point bending method recommended by the RILEM [58] and China DL/T5332-2005 "Norm for fracture test of hydraulic concrete" [59]. In addition, the dry shrinkage performance of HPFRCC was studied and analyzed at $20^{\circ} \mathrm{C}$ and $50 \% \mathrm{RH}$. Then, the load crack opening displacement curve, fracture energy, and dry shrinkage performance of HPFRCC with different steel fibers are compared and analyzed, and the influence of HPFRCC with different steel fiber content on the fracture performance and dry shrinkage performance is discussed, which lays a solid foundation for HPFRCC to be widely used in practical projects.

\section{Experimental Details and Methods}

2.1. Materials and Mix Proportions. For the tests described in this contribution, HPFRCC with five different amounts of steel fibers (SF) varying between 0 and $200 \mathrm{~kg} / \mathrm{m}^{3}$ has been prepared. Ordinary Portland cement (OPC) Type 42.5, fly ash (FA) class F with an average particle diameter of $5.4 \mu \mathrm{m}$, and silica fumes with an average particle size of
$0.03 \mu \mathrm{m}$ were used to produce the test samples. The chemical compositions of OPC, silica fumes, and fly ash are summarized in Table 1 . In addition, fine quartz sand $\left(Q_{s}\right)$ with a grain size of 0.2 to $0.35 \mathrm{~mm}$ and quartz powder $\left(Q_{p}\right)$ with a maximum grain size of $45 \mu \mathrm{m}$ were added. The composition of the matrix was optimized in a systematic way. Copper-plated steel fibers (SFs) with a length of $13 \mathrm{~mm}$ and a diameter of $0.2 \mathrm{~mm}$ were added to the fresh mix, the properties of the steel fiber in this paper are listed in Table 2, and the shape of the steel fibers is shown in Figure 1. Ordinary tap water is used as the mixing water. To improve the workability of the mix, the superplasticiser (SP) was added. The superplasticiser (SP) is a polycarboxylate superplasticiser from Jiaozhou (Qingdao, China), and its water reduction rate and solid content are $25 \%$ and $20 \%$, respectively. The compositions of the specimens are given in Table 3 . In addition, ordinary cement mortar test blocks were made for the comparative study of the fracture energy of HPFRCC. The materials of ordinary cement mortar test blocks were ordinary Portland cement ( $\mathrm{PO}$ 32.5), river sand after sieving (maximum size is $5 \mathrm{~mm}$ ), and tap water. The naming forms of specimens with different mix proportions are shown in Table 4 . The proportion and its mechanical properties are shown in Table 5.

2.2. Preparation of Test Specimens. All the raw materials poured into the mixer in sequence (quartz powder, fly ash, silica fume, cement, and quartz sand) are stirred evenly. And then, $80 \%$ water and superplasticisers were mixed evenly which were slowly added to the mixture at a low mixing speed, followed by pouring $20 \%$ water directly into the mixture. The steel fibers were then slowly added to the mixture at a low mixing speed within one minute, followed by a medium mixing speed for three minutes to achieve uniform fiber dispersion. The fresh mixture was cast into the corresponding moulds and vibrated on the vibration table for three minutes. The whole mixing process of materials is shown in Figure 2. After compaction in the steel form on a vibrating table, the specimens were allowed to harden in the laboratory covered with plastic sheets for 24 hours. Then, they were further cured in hot water at $80^{\circ} \mathrm{C}$ for 72 hours. And then, all specimens were removed and cured in a humid chamber at $T=20 \pm 2^{\circ} \mathrm{C}$ and $\mathrm{RH}>95 \%$ before testing.

2.3. Fluidity and Flexural Strength Test. The fluidity of the fresh mixture is determined by the reciprocating flow table method, and the specific experimental method is in accordance with the GB/T2419-2016 "Test method for fluidity of cement mortar." When the specimens are obtained from curing at the corresponding age, their flexural strength is measured with a cement mortar testing machine, with reference to the standard GB/T17671-2019 "Method of testing cement determination of strength." The optimal mix ratio of HPFRCC was determined from the results of fluidity and flexural strength and was applied to the subsequent experimental study. 
TABle 1: Chemical composition of ordinary Portland cement (OPC), silica fumes, and fly ash (FA) (\%).

\begin{tabular}{lcccccccc}
\hline Type & $\mathrm{CaO}$ & $\mathrm{SiO}_{2}$ & $\mathrm{Al}_{2} \mathrm{O}_{3}$ & $\mathrm{Fe}_{2} \mathrm{O}_{3}$ & $\mathrm{SO}_{3}$ & $\mathrm{~K}_{2} \mathrm{O}$ & $\mathrm{Na}_{2} \mathrm{O}$ & $\mathrm{TiO}_{2}$ \\
\hline OPC & 60.09 & 20.90 & 6.55 & 5.43 & 2.44 & 1.61 & 1.07 & 0.01 \\
Silica & 0.98 & 95.64 & 0.40 & 0.22 & 0.18 & 1.51 & 0.20 & 0.02 \\
fumes & 1.78 & 49.75 & 36.81 & 5.93 & 0.31 & 1.78 & 0.25 & 2.29 \\
FA & & & & & & & &
\end{tabular}

TABle 2: Properties of steel fiber (SF).

\begin{tabular}{lcccccc}
\hline Type & $L / D$ & $L(\mathrm{~mm})$ & $D(\mathrm{~mm})$ & $f_{t}(\mathrm{MPa})$ & $E(\mathrm{GPa})$ & $\rho\left(\mathrm{g} / \mathrm{m}^{3}\right)$ \\
\hline $\mathrm{SF}$ & 65 & 13 & 0.2 & 2600 & 200 & 8.0
\end{tabular}

Note. SF: steel fiber; $L / D$ : length to diameter ratio; $L$ : length; $D$ : diameter; $f_{t}$ : tensile strength; $E$ : elastic modulus; $\rho$ : density.

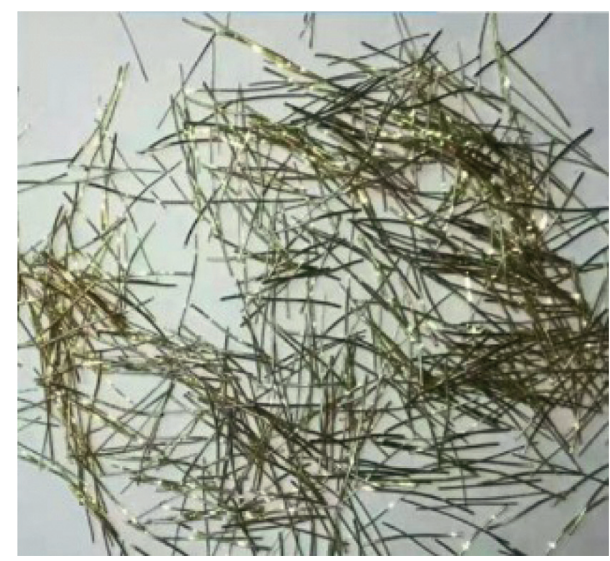

Figure 1: The shape of steel fibers.

2.4. Uniaxial Tensile Test. A dumbbell-shaped specimen was used for the uniaxial tensile test $[60,61]$. The size of the was specimen determined by the Japanese norms (Recommendations for the Design and Construction of High-Performance Fiber-Reinforced Cement Composites with Multiple Fine Cracks), as shown in Figure 3. The test was carried out on a Shimadzu AG-TS $250 \mathrm{kN}$ universal testing machine with a maximum load of $250 \mathrm{kN}$. The beam displacement accuracy was $0.001 \mathrm{~mm}$, the loading accuracy was $0.01 \mathrm{kN}$, and the beam moving speed was $0.1 \mathrm{~mm} / \mathrm{min}$. Two linear variable displacement transducers (LVDTs) affixed to a testing frame were used to measure the deformation of specimens. The specimen deformation value can be obtained from the average of the reading from the left and right sides of LVDTs. LVDT installation location is shown in Figure 3.

\subsection{Uniaxial Compression Test. Specimens of} $100 \mathrm{~mm} \times 100 \mathrm{~mm} \times 300 \mathrm{~mm}$ were cast for the determination of static strength. The shape of the specimen for the compression test is shown in Figure 4. Three samples of each batch were tested. The compressive strength measurements were conducted according to GB/T 17671-2005 (similar to ISO 697:1989) [62]. The test was carried out by a Changchun Vinte electro-hydraulic servo universal testing machine, with a maximum load of $2000 \mathrm{kN}$, a beam displacement accuracy of $0.001 \mathrm{~mm}$, and a load accuracy of $0.001 \mathrm{kN}$. The test machine is set to control the loading in a load mode with a loading rate of $0.1 \mathrm{MPa} / \mathrm{s}$. The centering and preloading process were repeated until the test specimen is completely centered and meets the preloading requirements, and then the uniaxial compression test is performed. The uniaxial compression test is performed in the displacement mode with a loading rate of $0.001 \mathrm{~mm} / \mathrm{s}$. The load is measured by a load sensor with a range of $2000 \mathrm{kN}$, the deformation is measured by the strain gauge, and the average value of the readings on the left and right sides is taken as the deformation value of the specimen.

2.6. Wedge Splitting Test. Specimens $200 \mathrm{~mm}$ (length) $\times$ $200 \mathrm{~mm}$ (height) $\times 40 \mathrm{~mm}$ (width) were used for the wedge splitting test as shown in Figure 5 [58]. The initial crack is reserved for casting, and the initial seam height ratio is $a / H=0.5$. The test device for wedge splitting is the same as the uniaxial tensile test device. An extensometer with a precision of $0.001 \mathrm{~mm}$ is placed on each side of the specimen to measure the crack opening displacement. The crack opening displacement value can be obtained from the average of the reading from the left and right sides of the extensometer. And then, the steel split joint is placed in the notch of the test piece, and the beam is moved and adjusted so that the wedge-shaped steel plate connected to the beam just contacts the split joint pulley. At that moment, the test is started, the load is controlled by displacement control loading, and the loading rate is $0.3 \mathrm{~mm} / \mathrm{min}$. The load and crack deformation readings are automatically recorded by the computer.

2.7. Three-Point Bending Test. The standard prism specimen of $160 \mathrm{~mm}$ (length) $\times 40 \mathrm{~mm}$ (height) $\times 40 \mathrm{~mm}$ (width) was used for the three-point (3-P) bending test $[63,64]$. The initial crack is reserved for casting, and the initial seam height ratio is $a / H=0.5$. The specimens were placed on the frame of three-point bending. The rigid frame and force on the specimen are shown in Figure 6. The test device for the three-point bending test is the same as the uniaxial tensile test device and the wedge splitting test device, and controlled loading is done with a displacement rate of $0.3 \mathrm{~mm} / \mathrm{min}$. In the test process, the load and the displacement of the loading point are recorded by the computer connected to the testing device.

2.8. Drying Shrinkage. In addition, some standard prisms with dimensions of $160 \mathrm{~mm}$ (length) $\times 40 \mathrm{~mm}$ (height) $\times$ $40 \mathrm{~mm}$ (width) have been cured in a water bath at $80^{\circ} \mathrm{C}$ for 72 hours after demoulding. They were then put in a standard curing room with $T=20 \pm 2^{\circ} \mathrm{C}$ and $\mathrm{RH}>95 \%$ until the age of 28 days. After that, the specimens were placed in the laboratory with the atmosphere of $20^{\circ} \mathrm{C}$ and $50 \% \mathrm{RH}$ for three months. The time-dependent moisture loss and drying shrinkage have been measured for these HPFRCC specimens. 
TABLE 3: The best mix selection range for HPFRCC.

\begin{tabular}{lccccc}
\hline$W / B$ & Cement & Silica fumes & Fly ash & $S / B$ & Quartz powder \\
\hline $0.19-0.21$ & $0.5-1$ & $0.25-0.35$ & $0-0.5$ & $0.68-1.08$ & $0.27-0.47$
\end{tabular}

TABle 4: Mix proportions of specimens.

\begin{tabular}{|c|c|c|c|c|c|c|}
\hline Name & $W / B$ & OPC & Silica fumes & FA & Quartz sand & Quartz powder \\
\hline $\mathrm{A}_{1}$ & 0.19 & 1 & 0.25 & 0 & 0.88 & 0.37 \\
\hline $\mathrm{A}_{2}$ & 0.2 & 1 & 0.25 & 0 & 0.88 & 0.37 \\
\hline $\mathrm{A}_{3}$ & 0.21 & 1 & 0.25 & 0 & 0.88 & 0.37 \\
\hline $\mathrm{A}_{4}$ & 0.22 & 1 & 0.25 & 0 & 0.88 & 0.47 \\
\hline $\mathrm{B}_{1}$ & 0.21 & 1 & 0.15 & 0 & 0.88 & 0.42 \\
\hline $\mathrm{B}_{2}$ & 0.21 & 1 & 0.2 & 0 & 0.88 & 0.37 \\
\hline $\mathrm{B}_{3}$ & 0.21 & 1 & 0.25 & 0 & 0.88 & 0.32 \\
\hline $\mathrm{B}_{4}$ & 0.21 & 1 & 0.3 & 0 & 0.88 & 0.27 \\
\hline $\mathrm{B}_{5}$ & 0.21 & 1 & 0.35 & 0 & 0.88 & 0.37 \\
\hline $\mathrm{C}_{1}$ & 0.21 & 1 & 0.25 & 0 & 0.68 & 0.37 \\
\hline $\mathrm{C}_{2}$ & 0.21 & 1 & 0.25 & 0 & 0.78 & 0.37 \\
\hline $\mathrm{C}_{3}$ & 0.21 & 1 & 0.25 & 0 & 0.88 & 0.37 \\
\hline $\mathrm{C}_{4}$ & 0.21 & 1 & 0.25 & 0 & 0.98 & 0.37 \\
\hline $\mathrm{C}_{5}$ & 0.21 & 1 & 0.25 & 0 & 1.08 & 0.37 \\
\hline $\mathrm{D}_{1}$ & 0.21 & 1 & 0.25 & 0 & 0.88 & 0.37 \\
\hline $\mathrm{D}_{2}$ & 0.21 & 0.9 & 0.25 & 0.1 & 0.88 & 0.37 \\
\hline $\mathrm{D}_{3}$ & 0.21 & 0.8 & 0.25 & 0.2 & 0.88 & 0.37 \\
\hline $\mathrm{D}_{4}$ & 0.21 & 0.7 & 0.25 & 0.3 & 0.88 & 0.37 \\
\hline $\mathrm{D}_{5}$ & 0.21 & 0.6 & 0.25 & 0.4 & 0.88 & 0.37 \\
\hline $\mathrm{D}_{6}$ & 0.21 & 0.5 & 0.25 & 0.5 & 0.88 & 0.37 \\
\hline
\end{tabular}

TABLE 5: Mix proportion and mechanical properties of ordinary cement mortar specimens.

\begin{tabular}{lccccc}
\hline Water-binder ratio & Cement $\left(\mathrm{kg} / \mathrm{m}^{3}\right)$ & Sand $\left(\mathrm{kg} / \mathrm{m}^{3}\right)$ & Water $\left(\mathrm{kg} / \mathrm{m}^{3}\right)$ & Flexural strength $(\mathrm{MPa})$ & Compressive strength $(\mathrm{MPa})$ \\
\hline 0.5 & 450 & 1350 & 225 & 5.86 & 34.6 \\
\hline
\end{tabular}

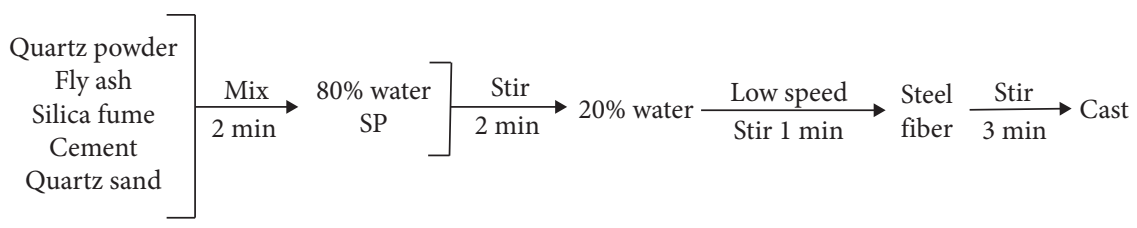

FIGURE 2: HPFRCC mixing process.

\section{Results and Discussion}

3.1. Fluidity and Flexural Strength. Through fluidity and flexural strength tests, the effects of HPFRCC fluidity and flexural strength at different water-to-binder ratios $(W /$ $B=0.19,0.2,0.21$, and 0.22$)$, silica fume contents $(0.15,0.20$, $0.25,0.30$, and 0.35$)$, sand-binder ratios $(0.68,0.78,0.88$, 0.98 , and 1.08$)$, and replacement quantity of fly ash $(0,0.1$, $0.2,0.3,0.4$, and 0.5$)$ were obtained. The specific results are shown in Figure 7.

In addition to the sand-binder ratio, when the waterbinder ratio, silica fume content, and fly ash replacement amount increase, the fluidity of the mixture increases linearly as can be seen in Figure 7. When the water-to-binder ratio is 0.21 , the mixture can quickly fill the mould under the action of vibration, and a large number of bubbles appear on the surface of the mixture during the vibration. After the fracture of the test piece, there are no holes in the cross section of the test piece, and the flexural strength is only $5.9 \%$ lower than that of the water-binder ratio 0.2 . The reason is that the increase in the mixing water increases the pores between the particles. When the amount of silica fumes is large, the fluidity of the mixture increases. This is mainly because the silica fume particles are spherical, the particles are very small, and the quartz powder particles are irregular in shape and are polygonal. Therefore, when the silica gel ratio is increased, the fluidity is also increased. The fluidity and flexural strength of the mixture are the largest, when the content of the silica fumes is 0.35 and quartz powder is 0.27 . When the sand-binder ratio increases, the fluidity of the mixture decreases clearly, while the flexural strength of the specimen increases first and then decreases; when the sand- 

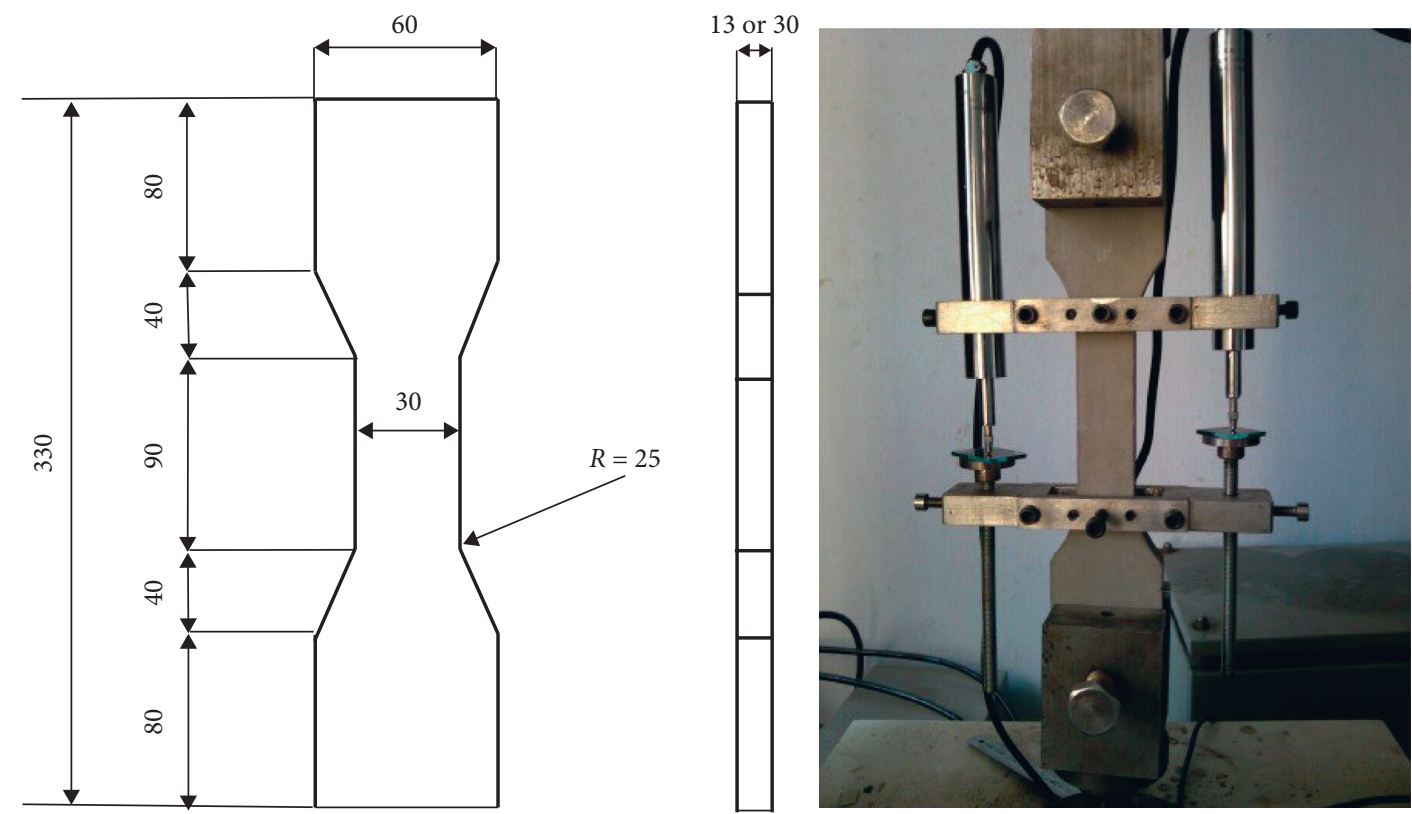

Figure 3: Uniaxial tensile test (mm).
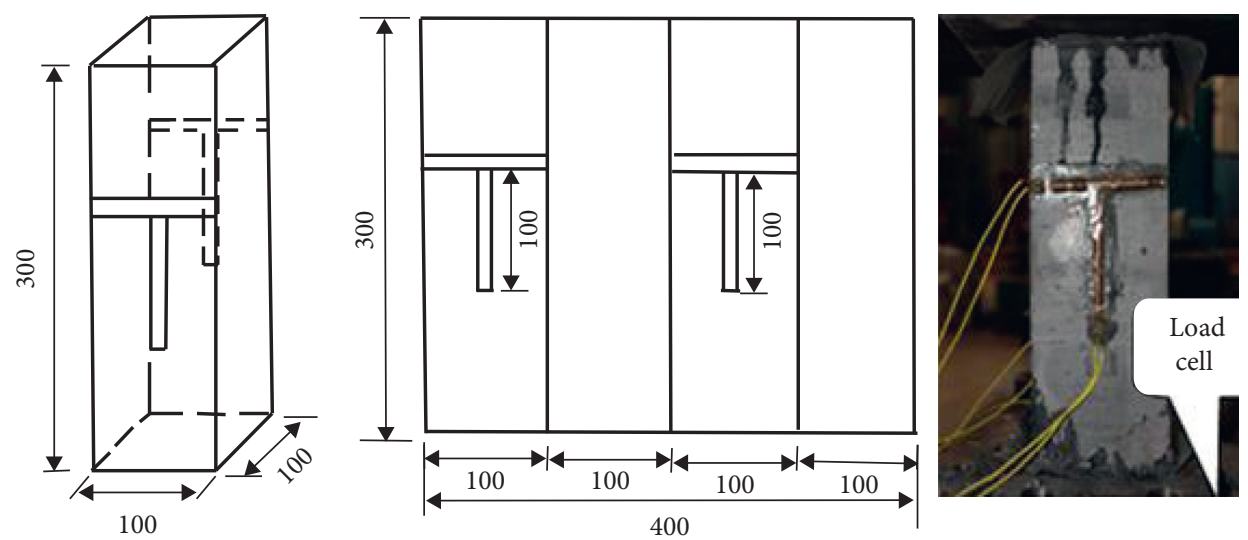

Figure 4: Uniaxial compression test specimen (mm).
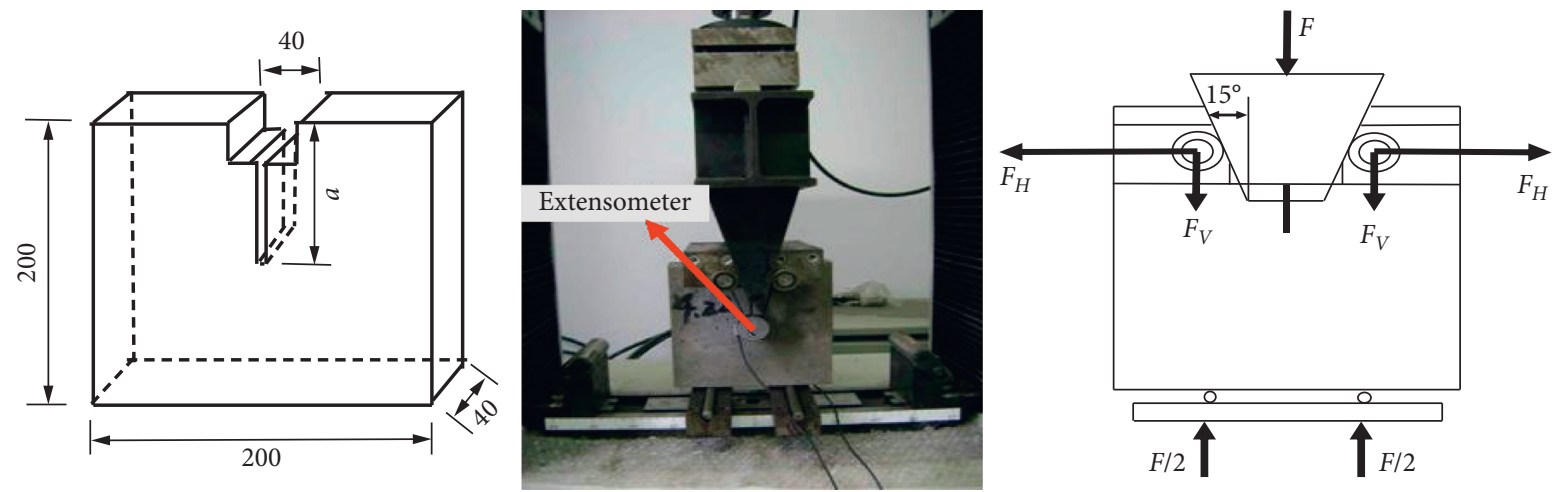

FIGURE 5: Wedge splitting test (mm).

binder ratio is 0.68 and 0.88 , the strength is $9.2 \%$ and $13.3 \%$, which is lower than that of 0.78 , mainly because there are particles of different sizes in the granular material system and the smaller particles have filling effect. The amount of cement replaced by fly ash increases, and its flexural strength increases first and then decreases; when it is $30 \%$, the 


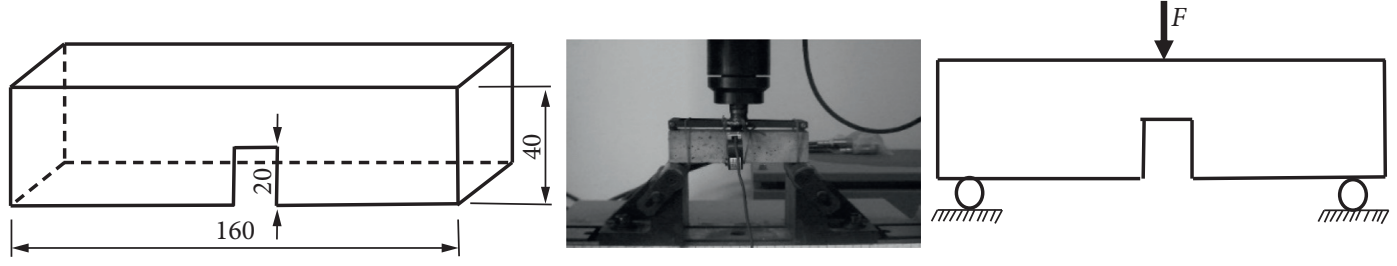

FIgURE 6: Three-point bending test (mm).

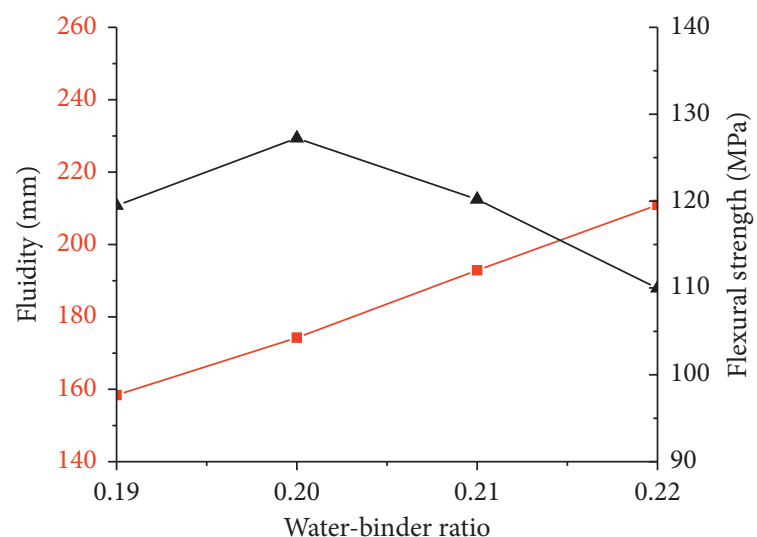

(a)

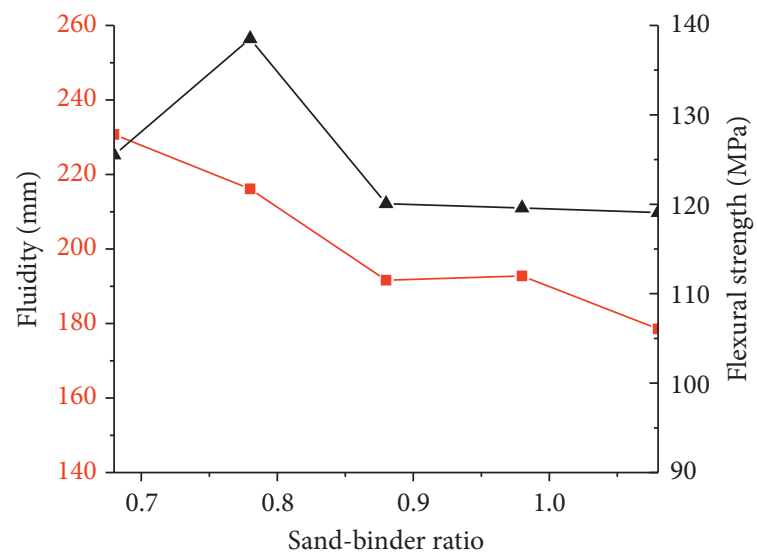

(c)

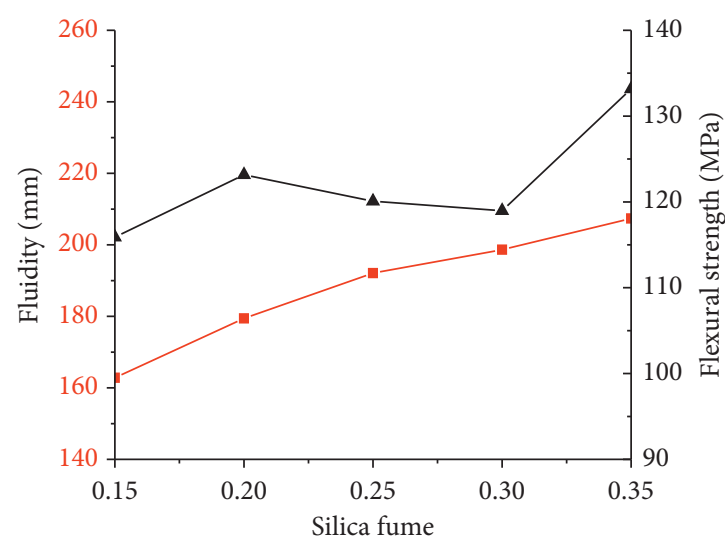

(b)

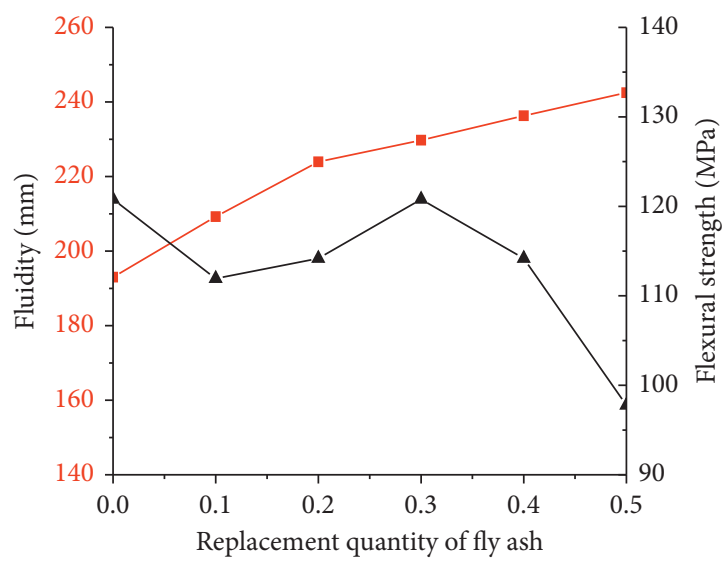

(d)

FIgURE 7: Effect of different variables on fluidity and flexural strength of HPFRCC.

strength of the specimen reaches the highest. Compared with the substitution number of 0 , the strength of HPFRCC increases by $1.2 \%$, but the fluidity of the mixture increases by $41 \mathrm{~mm}$, up to $233 \mathrm{~mm}$, and this is mainly because the reaction of fly ash to produce calcium hydroxide is earlier than that of cement hydration, and the strength of the calcium aluminate hydrate produced by the two reactions is lower than that of calcium silicate hydrate.

To sum up, considering the fluidity and flexural strength comprehensively, the optimal combination of HPFRCC obtained from the test is as follows: water-binder ratio is 0.21 and cement:silica fume:fly ash:quartz sand:quartz powder $=0.7: 0.35: 0.3: 0.78: 0.27$.
3.2. Tensile Stress-Strain Behavior. Figure 8 illustrates the tensile stress-strain behavior of HPFRCC with different steel fiber contents. Obviously, after the HPFRCC specimen is mixed with steel fibers, the initial stage of tension is still the elastic stage, and the stress increases linearly with the increase in strain. The ultimate tensile strength of HPFRCC increases continuously with the increase in the steel fiber content. The main reason is that the steel fiber has the ability to hinder and restrain the crack growth, so the ultimate tensile strength is improved.

It can be seen from the tensile test results of HPFRCC that when the steel fiber is added to HPFRCC, its tensile initial stage is still elastic, and the stress increases linearly 


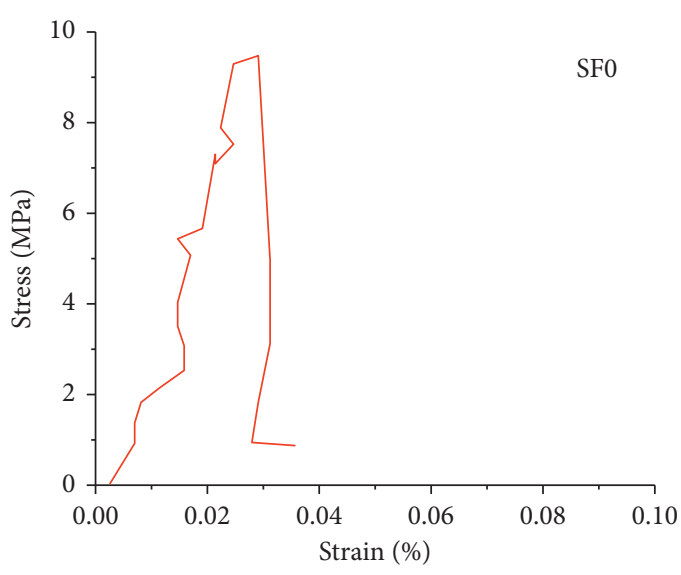

(a)

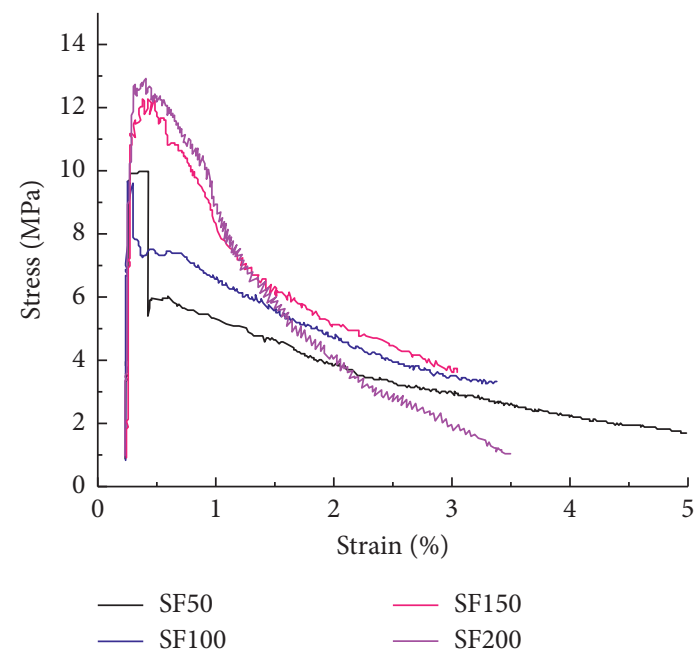

(b)

Figure 8: Tensile stress-strain diagrams of HPFRCC with different amount of steel fibers.

with the increase in strain. With the increase in the steel fiber content, the ultimate tensile strength of HPFRCC increases. The main reason is that the steel fiber can effectively prevent crack growth. As can be seen from Figure 8, when the steel fiber is not added, the stress of the specimen reaches the ultimate tensile strength and starts to drop vertically until the specimen fails. At this time, cracks appear in the sample, which is divided into two parts, showing obvious brittle characteristics. And, with the increase in steel fibers, the stress reduction section becomes slower and longer, which is mainly due to the continuous consumption of energy during the extraction process of steel fibers, which significantly improves the fracture resistance of the test piece. It can be concluded that the incorporation of steel fibers into HPFRCC can significantly improve the tensile strength of the material, increase the deformation capability of the material, and improve the ductility of the material, making it from brittle failure to plastic failure.

3.3. Compressive Strength. The uniaxial compression test was performed on HPFRCC specimens with a steel fiber content of $0-200 \mathrm{~kg} / \mathrm{m}^{3}$, and the compressive strength of the samples is shown in Figure 9.

It can be seen from Figure 9 that the steel fiber has a greater impact on the compressive strength of HPFRCC. With the increase in the steel fiber content, the compressive strength increases approximately linearly, and the increase rate is approximately unchanged when the steel fiber content is $0-150 \mathrm{~kg} / \mathrm{m}^{3}$, but when the amount of steel fiber is increased from $150 \mathrm{~kg} / \mathrm{m}^{3}$ to $200 \mathrm{~kg} / \mathrm{m}^{3}$, the increase rate slows down. This is mainly due to the good mechanical occlusion between steel fibers and the base material, which can improve the compressive strength of HPFRCC to a certain extent. However, with the increase in the amount of the steel fiber, the distribution of the steel fiber is uniform, and the inside of the specimen does not become dense, which causes the growth rate of compressive strength of HPFRCC to slow

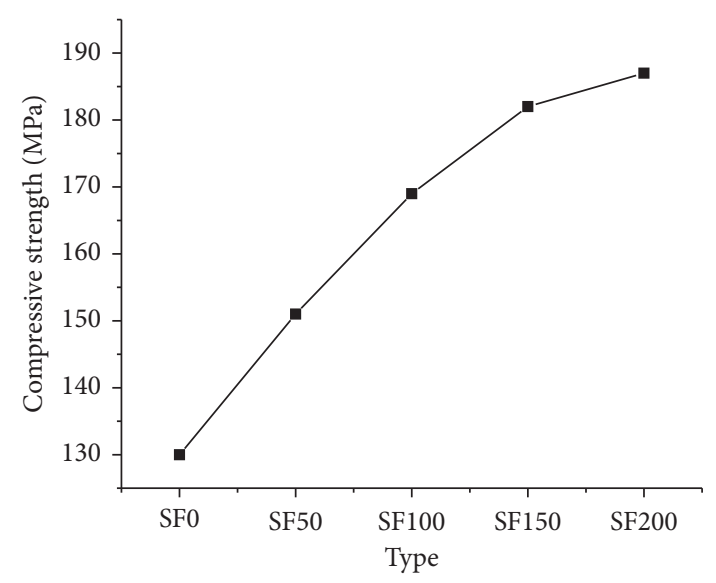

FIGURE 9: The compressive strength of HPFRCC with different steel fiber content.

down. Therefore, in the range of $0-200 \mathrm{~kg} / \mathrm{m}^{3}$, as the steel fiber content increases, the compressive strength does not increase linearly.

3.4. Results of Wedge Splitting Test. Firstly, the load-CMOD curves of cement mortar and HPFRCC specimens obtained by the wedge splitting test are compared. In Figure 10, different colors represent the test data obtained from three different samples with the same content of the steel fiber. From Figure 10, compared with HPFRCC without steel fiber, the peak load of the cement mortar test block is similar, but the crack opening displacement of HPFRCC is significantly larger than that of the ordinary cement mortar, so the fracture energy of HPFRCC is significantly higher than that of the ordinary cement mortar. However, during the test, it can be seen that when the load of the common cement mortar reaches the peak value, small cracks appear along the direction of the main cracks, and then the cracks gradually extend to a certain length with the wedge-shaped plate, and 


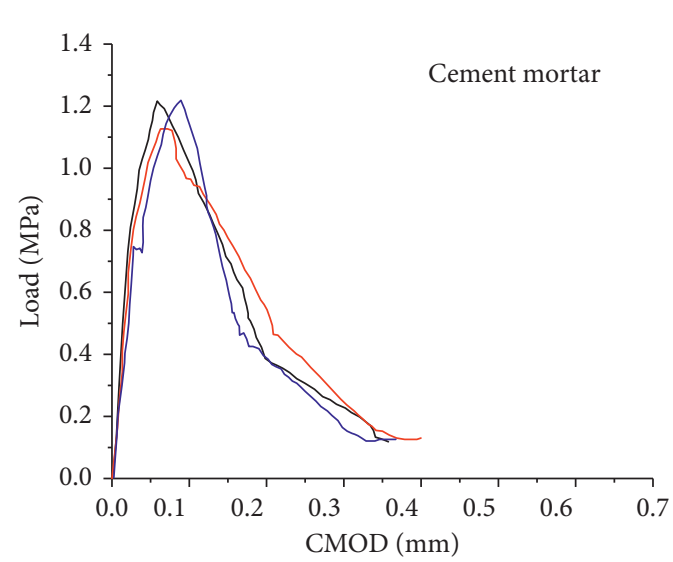

(a)

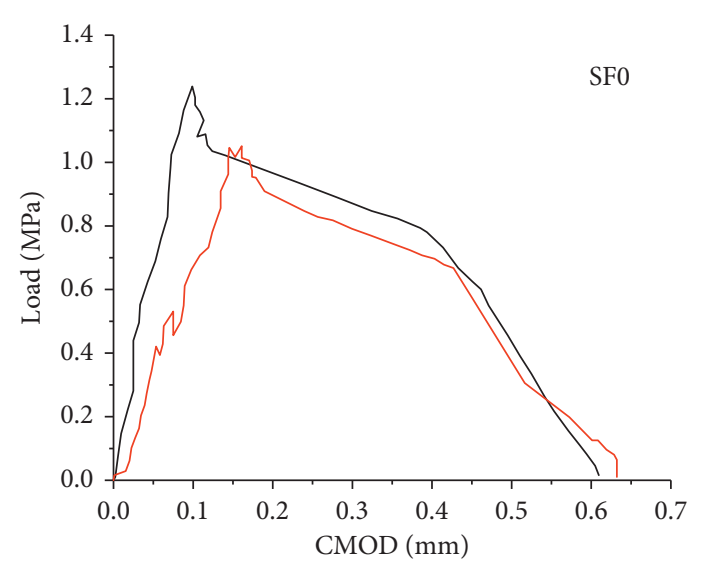

(b)

FIGURE 10: Load-CMOD curves of cement mortar and HPFRCC without steel fibers.

the specimen suddenly cracks into two halves. When the HPFRCC test specimen without the addition of steel fibers reaches the peak load, the test specimen suddenly shows brittle fracture along the main crack without any indication, indicating that HPFRCC is more brittle than the ordinary cement mortar, which is mainly due to its pure fine aggregates.

The fracture properties of HPFRCC with different content of steel fibers are further studied. The test results obtained by the wedge split test are shown in Figure 11 (the steel fiber content of $50 \mathrm{~kg} / \mathrm{m}^{3}$ could not be recorded due to the testing machine and operator). As can be seen from Figure 11(a), the stress of all specimens can be divided into three stages: crack initiation stage, crack propagation stage, and instability failure stage. From the load-CMOD curves, it can be seen that after the curve passes through the peak point, it descends approximately linearly in a gentle slope, which is very different from the curve of the ordinary mortar specimen. This is mainly due to the uniform and disordered distribution of the steel fiber inside the specimen after mixing with the steel fiber, so that the specimen does not fully develop along the direction of the main crack reserved in the specimen after reaching the cracking load, but at the same time, there are transverse cracks, which can also be obtained from the corresponding failure image of the specimen (Figure 11(b)). From the corresponding failure pictures, it is evident that with the increase in the steel fiber content, the crack opening displacement increases gradually. The main reason is that the steel fiber consumes the energy of crack growth in the process of slowly pulling out, which makes its fracture resistance significantly improved.

From Figure 11(b), it can be seen that there are many transverse cracks in the sample due to the existence of the steel fiber. It is mainly due to the uneven distribution of the steel fiber in the sample. To a certain extent, it shows that the wedge-shaped split test is not suitable for the experimental study of fracture performance of HPFRCC materials.

In the wedging split test, the maximum splitting force of the cement mortar specimen and the HPFRCC specimen was obtained, as shown in Figure 12.
It should not be ignored that compared with the cement mortar test block, the maximum splitting force of HPFRCC with the steel fiber is significantly increased. With the increase in the steel fiber content, the maximum splitting force increases significantly, mainly due to the good tensile strength of the steel fiber and good mechanical bite force with the matrix. During the failure of the test piece, the steel fiber exerted its tensile performance better, thereby increasing the maximum splitting force of the HPFRCC specimen.

3.5. Results of Three-Point Bending Test. By using the threepoint bending test to study the fracture performance of HPFRCC specimens with different steel fiber content, the test results are obtained as shown in Figure 13. The data in the figure are the average of the test results of three different samples with the same steel fiber content.

As can be seen from the figure, compared with the HPFRCC without steel fiber, the bearing capacity of HPFRCC with steel fiber is significantly enhanced, which is mainly due to the addition of the steel fiber, which increases the toughness and crack resistance of the specimen. Compared with the load-deformation curve of the specimen with a steel fiber content of $50-200 \mathrm{~kg} / \mathrm{m}^{3}$, it is obtained that as the amount of steel fiber increases, the fuller the load-deformation curve, the peak load and deformation also gradually increase, and the area under the curve gradually increases, i.e., the fracture energy increases. The main reason is that with the increase in the steel fiber content, the number of fibers per unit area increases, which increases the bonding force between the fiber and the matrix and improves the positive ability of the specimen. At the same time, the energy of crack growth is consumed in the process of slow drawing, which improves the fracture resistance of the steel fiber significantly.

The calculation formulas of fracture energy, characteristic length, and ductility index is shown in formulas (1)-(3) [65-67]. Also, the performance indicators for each mix ratio in the three-point bending test are shown in Table 6. 

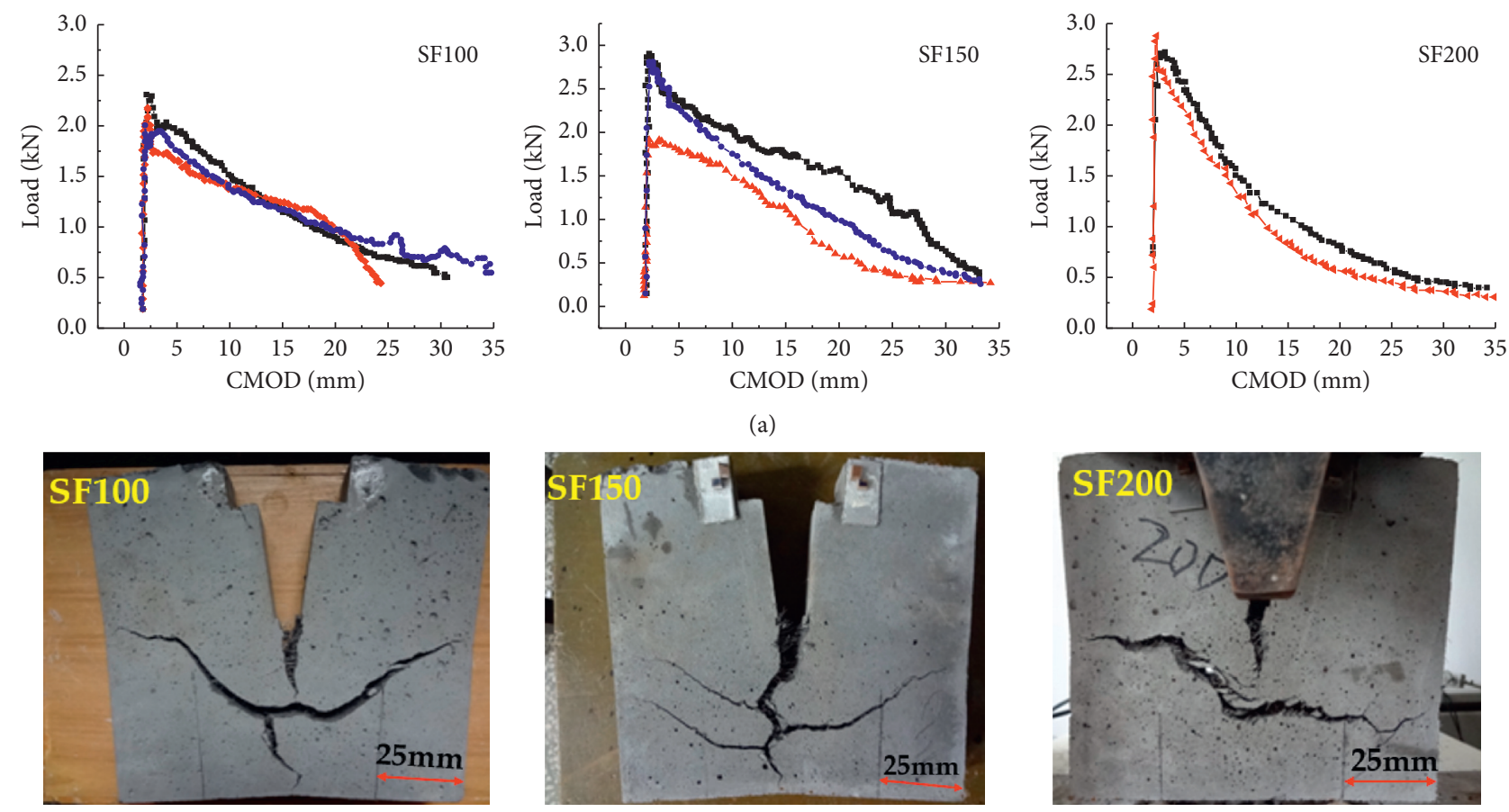

(b)

FIgure 11: (a) The load-CMOD curves of HPFRCC with $100 \mathrm{~kg} / \mathrm{m}^{3}$ to $200 \mathrm{~kg} / \mathrm{m}^{3}$ of steel fibers during the wedge splitting test. (b) Cracking form of a specimen with different contents of steel fibers.

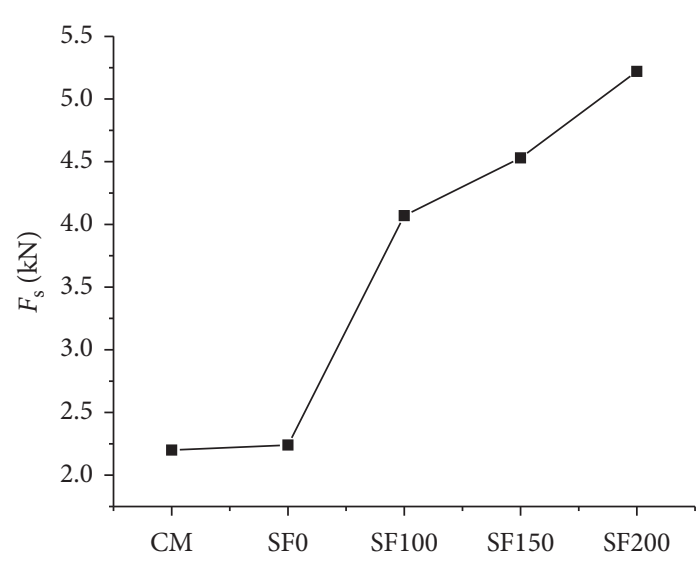

FIGURE 12: The maximum splitting force for different specimens.

$$
\begin{aligned}
& G_{f}=\frac{W_{0}+W \delta_{0}}{A_{\text {lig }}}, \\
& l_{\mathrm{ch}}=\frac{G_{f} E}{\left(f_{t}\right)^{2}}, \\
& D_{u}=\frac{G_{f}}{P_{\max }},
\end{aligned}
$$

where $W_{0}$ is the area under the load-CMOD (or deflection) curves up to rupture of the specimen $(\mathrm{N} \cdot \mathrm{mm}), W$ stands for the deadweight of the specimen, $\delta_{0}$ is the maximum deflection, $A_{\text {lig }}$ is the surface area of the broken ligament $\left(\mathrm{mm}^{2}\right), E$ is the elastic modulus, $f_{t}$ is the tensile strength of the materials, and $P_{\max }$ is the maximum load.

It can be seen from Figure 14 that the maximum load, fracture energy, characteristic length, and ductility index of HPFRCC notched beams increase significantly after the addition of steel fibers. Compared to that without the steel fiber, the maximum load, fracture energy, characteristic length, and ductility index are increased about 1-5 times, 100-320 times, 100-190 times, and 60-70 times, respectively. It can be seen that the effect of strengthening and toughening with steel fibers are very obvious. It can also be seen from the test results that the two indexes of characteristic length and ductility index do not have a unified trend with the increase in the steel fiber content, and they reach the highest when the steel fiber content is $100 \mathrm{~kg} / \mathrm{m}^{3}$ and $50 \mathrm{~kg} / \mathrm{m}^{3}$, respectively. However, the ductility index has a little change after adding different quantities of steel fibers, which shows that the difference of the resistance to deformation of HPFRCC with a steel fiber content of $50 \mathrm{~kg} / \mathrm{m}^{3}$ and $200 \mathrm{~kg} / \mathrm{m}^{3}$ is not significant, and when HPFRCC is used for special purposes, the cost of materials can be greatly reduced.

It can be seen from Figure 14 that there is a clear linear relationship between deflection, maximum load, and fracture energy and steel fiber content. To verify this statement, a linear regression was performed on the relationship between each fracture index and the amount of steel fiber as shown in Table 7, and it was found that they follow the rules shown in Table 7.

From the formulas in the table, it can be seen that the maximum load, fracture energy, and deflection are linear 


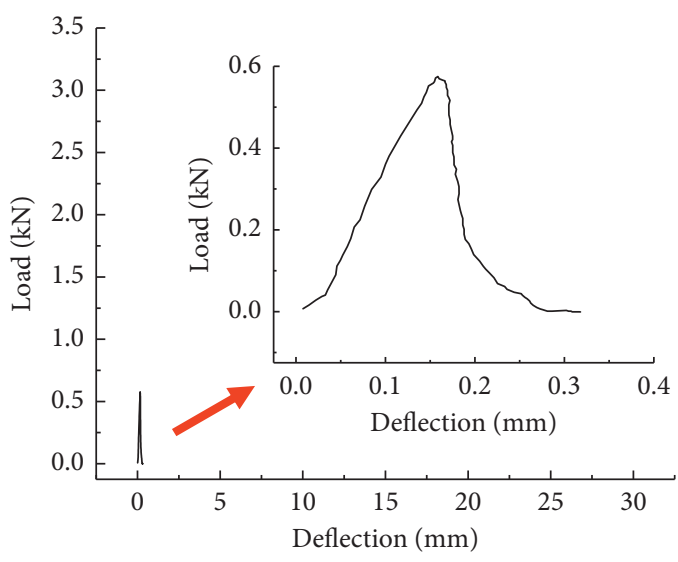

- SF0

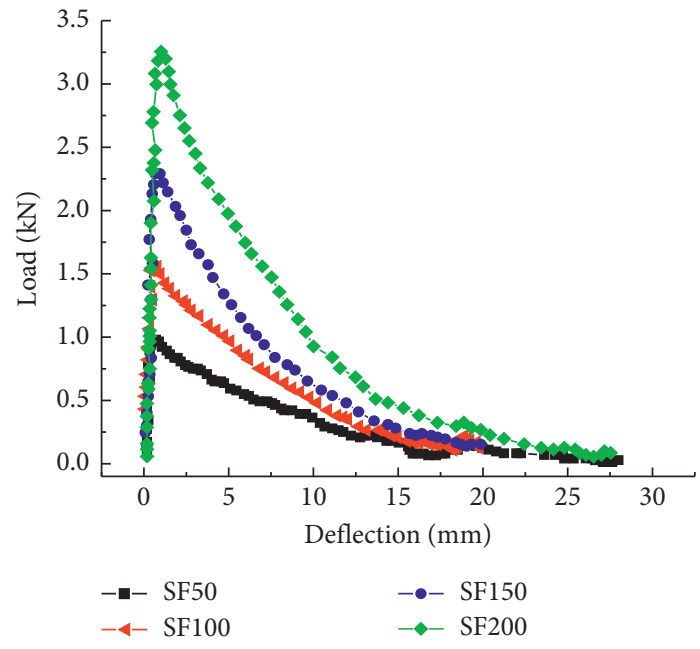

(b)

Figure 13: The load-deflection curves of HPFRCC with different amount of steel fibers between 0 and $200 \mathrm{~kg} / \mathrm{m}^{3}$ obtained by the three-point bending test.

TABLE 6: Facture performance indicators of HPFRCC.

\begin{tabular}{|c|c|c|c|c|c|c|}
\hline Type & $\delta_{0}(\mathrm{~mm})$ & $E(\mathrm{GPa})$ & $P_{\max }(\mathrm{kN})$ & $G_{f}\left(\mathrm{~J} / \mathrm{m}^{2}\right)$ & $l_{\mathrm{ch}}(\mathrm{m})$ & $D_{u}\left(\mathrm{~m}^{-1}\right)$ \\
\hline SF0 & 0.3 & 42.41 & 0.642 & 92.11 & 0.049 & 0.143 \\
\hline SF50 & 17.85 & 43.16 & 1.031 & 10480 & 4.969 & 10.164 \\
\hline SF100 & 19.68 & 49.56 & 1.652 & 16034 & 8.257 & 9.705 \\
\hline SF150 & 21.83 & 40.64 & 2.303 & 19972 & 5.156 & 8.672 \\
\hline SF200 & 25.19 & 37.76 & 3.191 & 31744 & 7.550 & 9.942 \\
\hline
\end{tabular}

Note. $\delta_{0}$ : deflection; $E$ : elastic modulus; $P_{\max }$ : maximum load; $G_{f}$ : fracture energy; $l_{\mathrm{ch}}$ : characteristic length; $D_{u}$ : ductility index.

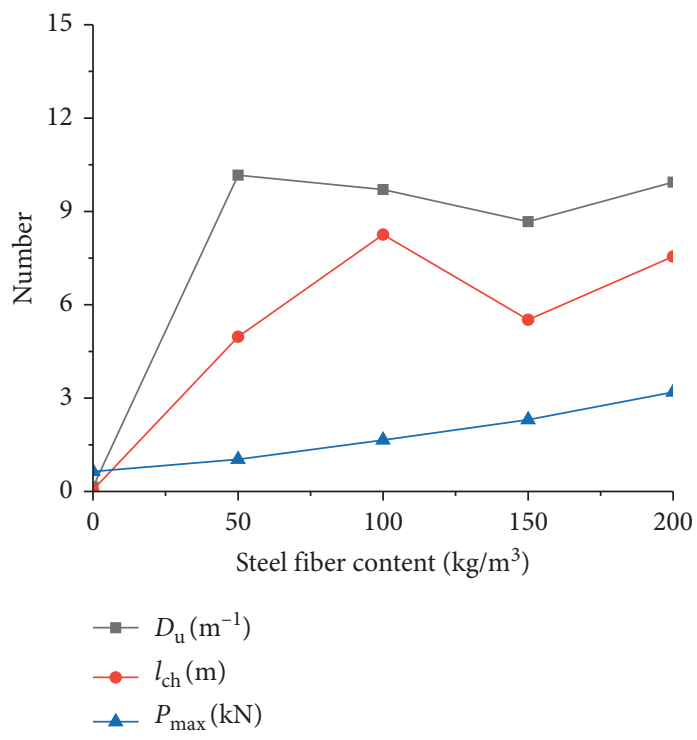

(a)

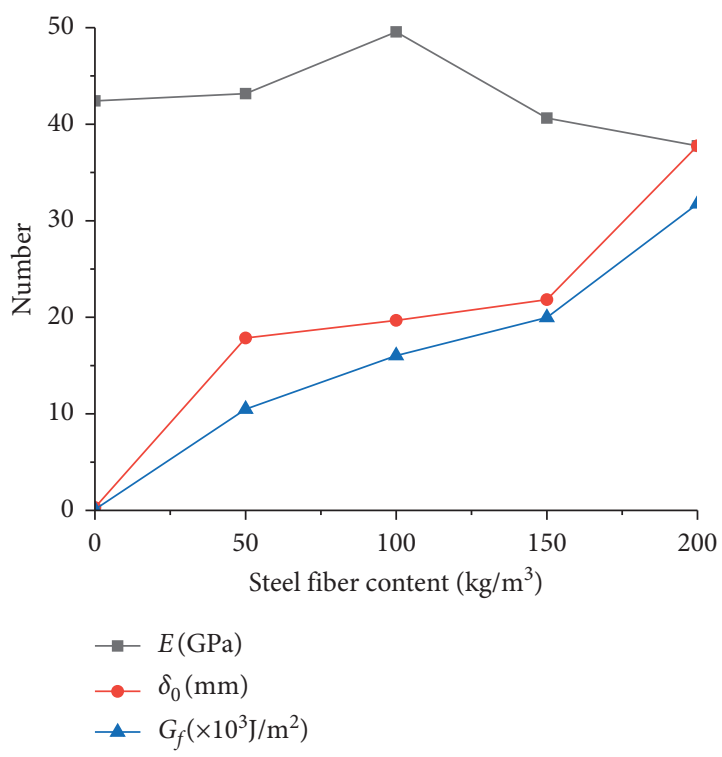

(b)

Figure 14: Relationship between fracture performance indicators and steel fiber content. 
TABLE 7: Linear regression between fracture performance index and steel fiber content for HPFRCC.

\begin{tabular}{cccc}
\hline & Index & Regression equation & $R^{2}$ \\
\hline & $y=P_{\max }$ & $y=0.01274 x+0.4898$ & 0.97489 \\
& $y=G_{f}$ & $y=145.59156 x+1105.266$ & 0.95927 \\
$x=$ steel fiber & $y=\delta_{0}$ & $y=0.1075 x+6.218$ & 0.76622 \\
& $y=E$ & $y=-0.02364 x+45.07$ & 0.18383 \\
& $y=l_{\text {ch }}$ & $y=0.04538 x+2.1732$ & 0.55651 \\
& $y=D_{u}$ & $y=0.03621 x+4.104$ & 0.44805 \\
\hline
\end{tabular}

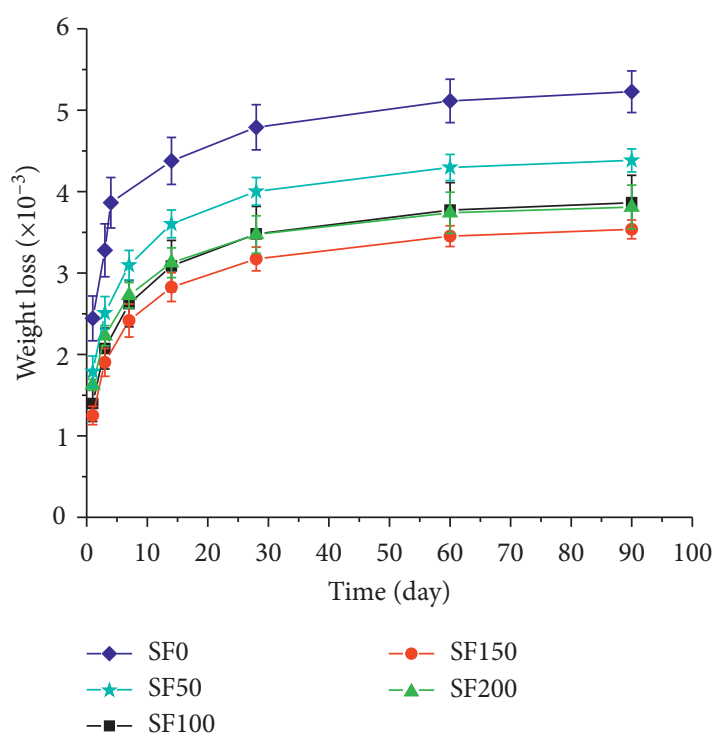

(a)

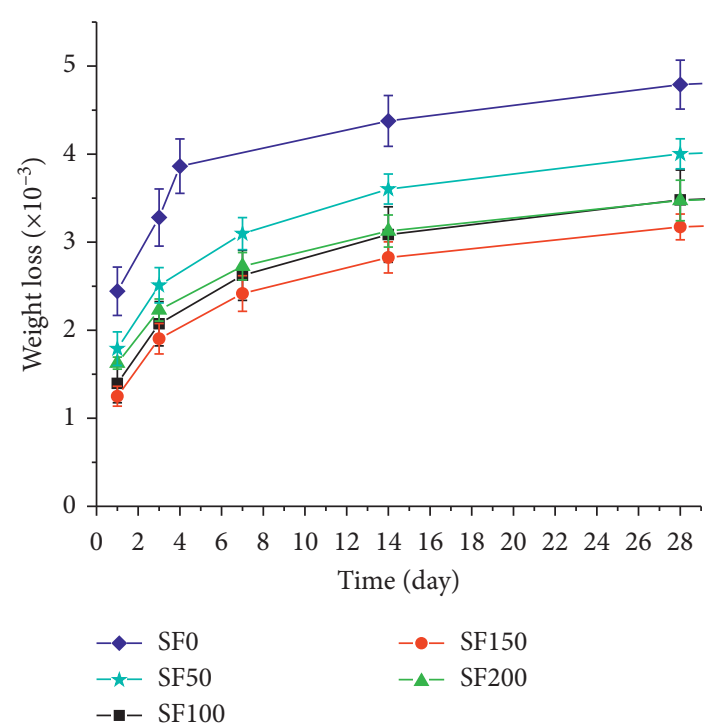

(b)

Figure 15: Weight loss of HPFRCC with different content of steel fibers under $50 \% \mathrm{RH}$ and $20^{\circ} \mathrm{C}$.

and positively related to the amount of the steel fiber. This indicates that the maximum load, fracture energy, and deflection increase with the increase in the steel fiber content, which proves that the addition of the steel fiber in HPFRCC can improve its own fracture energy carrying capacity and deformation capacity. The main reason is that a large amount of crack growth energy can be consumed during the process of steel fibers pull out, and its fiber bridging ability can effectively inhibit the development of cracks and fully exert its own tensile properties.

3.6. Dry Shrinkage. Figures 15 and 16 show the weight loss and shrinkage of the HPFRCC with different steel fiber contents under the conditions of $50 \% \mathrm{RH}$ and $20^{\circ} \mathrm{C}$ through the dry shrinkage test.

It can be seen from Figure 15 that the weight loss rate of each mix proportioning specimen increases rapidly in the first 14 days under a dry environment, and the first 14 days is the most important period of weight loss. After 14 days, the weight loss of the specimen rises slowly with a small increase. Taking the test piece without the steel fiber as an example, when the drying age is $1 \mathrm{~d}, 3 \mathrm{~d}, 7 \mathrm{~d}$, and $14 \mathrm{~d}$, the weight loss rate of the test piece is $47 \%, 63 \%, 74 \%$, and $84 \%$ of the $90 \mathrm{~d}$ water loss rate, respectively. This is mainly because the water in the cement matrix diffuses from inside to outside, and the water lost in the early stage is mainly the water near the surface of the specimen. This part of water is easy to lose, and the loss rate is fast, while the water lost in the later stage is the water inside or even in the center of the test piece, which is difficult to spread, and the loss rate is slow.

It can also be seen from Figure 15 that, after adding steel fibers, the water loss rate of the test specimens at each dry age is smaller than that without steel fibers. The $90 \mathrm{~d}$ weight loss rates of steel fiber specimens mixed with $50 \mathrm{~kg} / \mathrm{m}^{3}, 100 \mathrm{~kg} /$ $\mathrm{m}^{3}, 150 \mathrm{~kg} / \mathrm{m}^{3}$, and $200 \mathrm{~kg} / \mathrm{m}^{3}$ were $84 \%, 74 \%, 68 \%$, and $73 \%$ of the water loss rate of the specimens without steel fibers. This is mainly due to the addition of steel fibers to HPFRCC, which is equivalent to replacing the same volume of matrix material with steel fibers in the test sample.

It can be seen from Figure 16 that the shrinkage deformation of specimens with different mix proportions increases rapidly in the first 14 days under a dry environment, and the first 14 days is the most important period of shrinkage deformation. After 14 days, the shrinkage deformation of the specimen rises slowly with a small increase. This is mainly because the dry shrinkage of the cement matrix is mainly caused by the loss of water. The more the loss of water, the greater the dry shrinkage deformation. The shrinkage deformation of specimens without steel fiber was 


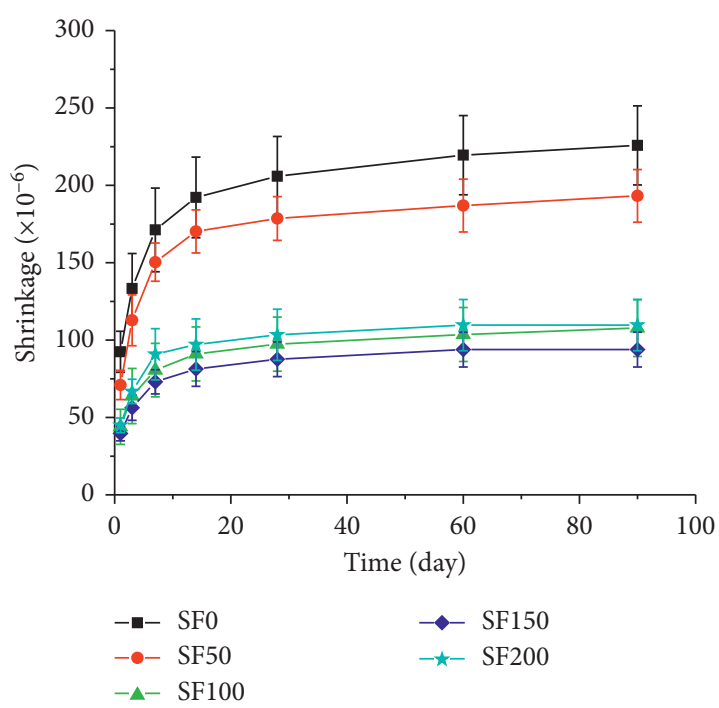

(a)

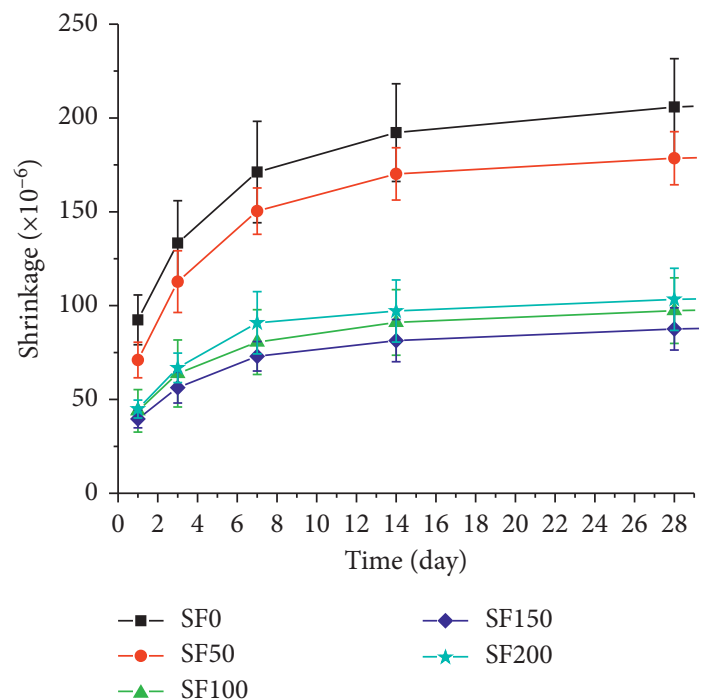

(b)

Figure 16: Shrinkage of HPFRCC with different content of steel fibers under $50 \% \mathrm{RH}$ and $20^{\circ} \mathrm{C}$.

$41 \%, 59 \%, 76 \%$, and $85 \%$ of the shrinkage deformation of 90 days, respectively, when the drying age was $1 \mathrm{~d}, 3 \mathrm{~d}, 7 \mathrm{~d}$, and $14 \mathrm{~d}$. The shrinkage deformation ratio was close to the water loss ratio. It can also be seen from Figure 16 that the shrinkage deformation value of the HPFRCC specimen with steel fibers is much smaller than that without steel fibers. At the same time, the slope of the shrinkage deformation curve of HPFRCC specimens with steel fibers is significantly lower than that of steel specimens without steel fibers after 28 days. This shows that the restriction of shrinkage and deformation after the incorporation of steel fibers is very effective.

\section{Conclusions}

In this paper, high-performance concrete with high strength and good working performance is made from Qingdao local materials. Based on this, a series of studies on the uniaxial tensile, fracture, and dry shrinkage properties of HPFRCC are carried out, and the following conclusions can be drawn:

(1) The cement-based high-strength matrix is brittle, but fracture energy can be increased substantially by the addition of steel fibers. The composite material becomes more ductile, and the load bearing capacity increases.

(2) It can be seen from the relationship between the content of steel fibers and the fracture performance indicators that with the increase in the steel fiber content, most fracture performance indexes (fracture energy $G_{f}$, deformation $\delta_{0}$, maximum load $P_{\max }$, ductility index $D_{u}$, and characteristic length $l_{\mathrm{ch}}$ ) increase. The fracture energy increases the most, which shows that the ductility and bearing capacity of HPFRCC can be significantly improved by increasing the steel fiber content.

(3) The wedging split test shows that the brittleness of HPFRCC without steel fibers is much greater than that of the ordinary cement mortar. After the steel fiber is added to the specimen, the stress in the specimen is distributed uniformly and disorderly, so that the crack does not fully develop along the direction of the main crack reserved in the specimen after the specimen reaches the cracking load, but at the same time, the transverse crack appears, and the ideal performance parameters are not obtained. This indicates that the wedging split test is not suitable for the study of the fracture performance of HPFRCC.

(4) After adding steel fibers, the strengthening and toughening effect of HPFRCC are very obvious. The maximum load, fracture energy, characteristic length, and ductility index of notched beams are all increased significantly. Between them, the fracture energy and maximum load increased almost linearly with the steel fiber content.

(5) The water loss and shrinkage deformation of HPFRCC increased rapidly in the first 14 days in the dry environment, and the first 14 days is the most important period of shrinkage. After 14 days, the weight loss and shrinkage deformation of HPFRCC increased slowly with little increase. But, the addition of steel fibers decreased the moisture diffusion, and consequently the drying shrinkage of HPFRCC.

\section{Data Availability}

The data used to support the findings of this study are available from the corresponding author upon request.

\section{Conflicts of Interest}

The authors declare that there are no conflicts of interest regarding the publication of this paper. 


\section{Authors' Contributions}

Weina Guo was responsible for conceptualization, methodology, and writing-original draft preparation; Peng Zhang was responsible for examination, writing-review-and editing, supervision, and project administration.

\section{Acknowledgments}

This research was funded by the National Natural Science Foundation of China, grant numbers 51922052, 51778309, and U1706222; Natural Science Foundation of Shandong Province, grant number ZR2018JL018; Open Research Fund Program of State Key Laboratory of Hydroscience and Engineering, grant number SKLHSE-2019-C-04.

\section{References}

[1] S. P. Shah and C. Ouyang, "Mechanical behavior of fiberreinforced cement-based composites," Journal of the American Ceramic Society, vol. 74, no. 11, pp. 2727-2953, 1991.

[2] A. Nanni and J. Aziz, "RCC pavement reinforced with steel fibers," Concrete International, vol. 11, no. 3, pp. 64-69, 1989.

[3] V. S. Gopalaratnam, S. P. Shah, B. Gordon et al., "Fracture toughness of fiber reinforced concrete," ACI Materials Journal, vol. 88, no. 4, pp. 339-353, 1991.

[4] D. Soulioti, N. M. Barkoula, A. Paipetis, T. E. Matikas, T. Shiotani, and D. G. Aggelis, "Acoustic emission behavior of steel fibre reinforced concrete under bending," Construction and Building Materials, vol. 23, no. 12, pp. 3532-3536, 2009.

[5] J. Matikas, A. Sharma, and K. Grauf, "Mechanical properties of concrete with steel and polypropylene fibres at elevated temperatures," Fibers, vol. 7, no. 2, 2019.

[6] N. T. Tran, T. K. Tran, J. K. Jeon, J. K. Park, and D. J. Kim, "Fracture energy of ultra-high-performance fiber-reinforced concrete at high strain rates," Cement and Concrete Research, vol. 79, pp. 169-184, 2016.

[7] L. Tran, S. R. Ferreira, V. Krelani et al., "Effect of natural fibers on the self-healing capacity of high performance fiber reiforced cementitious composites," in Proceedings of the 2014 International Conference on Strain-Hardening Cement-Based Composites SHCC 2014: Strain-Hardening Cement-Based Composites, Dordrecht, Netherlands, 2014.

[8] C. Zanuy, S. Gonzalo, and D. Ulzurrún, "Impact performance of low-fiber content HPFRCC: from material to structural behavior," in Proceedings of the 2017 International Conference on Strain-Hardening Cement-Based Composites SHCC 2017: Strain-Hardening Cement-Based Composites, Dresden, Germany, September 2017.

[9] K. H. Hoang and N. V. Tue, "Comparative flexural and tensile behaviours of ultra-high performance fibre reinforced concrete with different steel fibres," in Proceedings of the 2017 International Conference on Strain-Hardening Cement-Based Composites SHCC 2017: Strain-Hardening Cement-Based Composites, Dresden, Germany, September 2017.

[10] S. Kim, H. Jung, and C. Park, "Effect of steel fiber volume fraction and aspect ratio type on the mechanical properties of SIFCON-based HPFRCC," Structural Engineering and Mechanics, vol. 65, no. 2, pp. 163-171, 2018.
[11] M. Tóth, B. Bokor, and A. Sharma, "Anchorage in steel fiber reinforced concrete-concept, experimental evidence and design recommendations for concrete cone and concrete edge breakout failure modes," Engineering Structures, vol. 181, pp. 60-75, 2019.

[12] T. Fukuhara, T. Kanakubo, and A. Ogawa, "Study on the influence of the fiber orientation to the mechanical performance of HPFRCC," in Proceedings of the 14th World Conference on Earthquake Engineering, Beijing, China, October 2008.

[13] C. Zanotti, N. Banthia, and G. Plizzari, "Crack growth resistance of concrete-HPFRCC interface," in Proceedings of the 2011 International Conference on Strain-Hardening Cement-Based Composites SHCC 2011: Strain-Hardening Cement-Based Composites, Rio de Janeiro, Brazil, December 2011.

[14] M. H. Aliabadi, Q. Li, L. Li et al., "Tensile response and fracture process of high-performance hybrid fiber-reinforced cement composites," Key Engineering Materials, vol. 324, pp. $715-718,2006$.

[15] L. S. Flanders and E. N. Landis, "Experimental measurements of energy dissipation in fiber reinforced ultra high performance concrete under different loading conditions," in Proceedings of the 2014 International Conference on Strain-Hardening Cement-Based Composites SHCC 2014: Strain-Hardening Cement-Based Composites, Dordrecht, Netherlands, November 2014.

[16] B. Jang-Bae, W.-S. Lee, E. Jeon et al., "Experimental study on the mechanical properties of HPFRCC with fiber volume fraction of PVA fiber," in Proceedings of the 2006 Korea Concrete Institute Conference, pp. 653-656, Seoul, Republic of Korea, 2006.

[17] D.-Y. Yoo, S. Kim, G.-J. Park, and J.-J. Park, "Residual performance of HPFRCC exposed to fire-effects of matrix strength, synthetic fiber, and fire duration," Construction and Building Materials, vol. 241, pp. 1-19, 2020.

[18] Y. Wang, Y. Cao, P. Zhang et al., "Water absorption and chloride diffusivity of concrete under the coupling effect of uniaxial compressive load and freeze-thaw cycles," Construction and Building Materials, vol. 209, pp. 566-576, 2019.

[19] X. Wei, X. Cai, and P. Wu, "EFFECTIVENESS of fabricating high performance fiber reinforced cementitious composite (HPFRCC) using high volume steel slag powder," in Proceeedings of the 2017 International Conference on StrainHardening Cement-Based Composites SHCC 2017: StrainHardening Cement-Based Composites, Dresden, Germany, September 2017.

[20] D.-Y. Yoo, J.-J. Park, and S.-W. Kim, "Fiber pullout behavior of HPFRCC: effects of matrix strength and fiber type," Composite Structures, vol. 174, pp. 263-276, 2017.

[21] J. Bao, S. Li, P. Zhang et al., "Influence of the incorporation of recycled coarse aggregate on water absorption and chloride penetration into concrete," Construction and Building Materials, vol. 239, Article ID 117845, 2020.

[22] K. G. Kuder and S. P. Shah, "Processing of high-performance fiber-reinforced cement-based composites," Construction and Building Materials, vol. 24, no. 2, pp. 181-186, 2010.

[23] M. Fakharifar, A. Dalvand, M. Arezoumandi, M. K. Sharbatdar, G. Chen, and A. Kheyroddin, "Mechanical properties of high performance fiber reinforced cementitious composites," Construction and Building Materials, vol. 71, pp. 510-520, 2014.

[24] M. Sharbatdar and T. Miyashita, "Tensile stress-strain relationship of high-performance fiber reinforced cement 
composites," in Proceedings of the 14th World Conference on Earthquake Engineering, Beijing, China, 2008.

[25] S. Gwon and M. Shin, "Direct-tensile and flexural strength and toughness of high-strength fiber-reinforced cement composites with different steel fibers," Journal of Asian Concrete Federation, vol. 2, no. 1, pp. 67-80, 2016.

[26] D. Kumar and M. Daugevičius, "Influence of HPFRCC compressive strength and confinement on concrete," Engineering Structures and Technologies, vol. 11, no. 2, pp. 55-56, 2019.

[27] R. Nilforoush, M. Nilsson, and L. Elfgren, "Experimental evaluation of tensile behaviour of single cast-in-place anchor bolts in plain and steel fibre-reinforced normal- and highstrength concrete," Engineering Structures, vol. 147, pp. 195206, 2017.

[28] J. W. Bao, S. B. Xue, P. Zhang, Z. Dai, and Y. F. Cui, "Coupled effects of sustained compressive loading and freeze-thaw cycles on water penetration into concrete," Structural Concrete, 2020.

[29] P. Zhang, D. Li, Y. Qiao et al., "Effect of air entrainment on the mechanical properties, chloride migration, and microstructure of ordinary concrete and fly ash concrete," Journal of Materials in Civil Engineering, vol. 30, pp. 1-9, 2018.

[30] H. Yazici, H. Yigiter, A. S. Karabulut et al., "Utilization of fly ash and ground granulated blast furnace slag as an alternative silica source in reactive powder concrete," Fuel, vol. 87, no. 12, pp. 2041-2407, 2018.

[31] H. Yazıc1, M. Y. Yardımcı, S. Aydin et al., "Mechanical properties of reactive powder concrete containing mineral admixtures under different curing regimes," Construction and Building Materials, vol. 23, no. 3, pp. 1223-1231, 2009.

[32] J. Dugat, N. Roux, and G. Bernier, "Mechanical properties of reactive powder concretes," Materials and Structures, vol. 29, no. 4, pp. 233-240, 1996.

[33] S. L. Yang, S. G. Millard, M. N. Soutsos, S. J. Barnett, and T. T. Le, "Influence of aggregate and curing regime on the mechanical properties of ultra-high performance fibre reinforced concrete (UHPFRC)," Construction and Building Materials, vol. 23, no. 6, pp. 2291-2298, 2009.

[34] K. Barnett, T. Mueller, and Y. Ribakov, "Effect of steel fibres on mechanical properties of high-strength concrete," Materials \& Design (1980-2015), vol. 31, no. 5, pp. 2604-2615, 2010.

[35] S. Xue, P. Zhang, J. Bao, L. He, Y. Hu, and S. Yang, "Comparison of mercury intrusion porosimetry and multi-scale $\mathrm{X}$-ray CT on characterizing the microstructure of heat-treated cement mortar," Materials Characterization, vol. 160, Article ID 110085, 2020.

[36] P. Zhang, F. H. Wittmann, M. Vogel, H. S. Müller, and T. Zhao, "Influence of freeze-thaw cycles on capillary absorption and chloride penetration into concrete," Cement and Concrete Research, vol. 100, pp. 60-67, 2017.

[37] Z. Kaiyue, Y. Qiao, P. Zhang, J. Bao, and Y. Tian, "Experimental and numerical study on chloride transport in cement mortar during drying process," Construction and Building Materials, Article ID 119655, 2020.

[38] Z. Wu, C. Shi, W. He, and D. Wang, "Static and dynamic compressive properties of ultra-high performance concrete (UHPC) with hybrid steel fiber reinforcements," Cement and Concrete Composites, vol. 79, pp. 148-157, 2017.

[39] G. M. Ren, H. Wu, Q. Fang, and J. Z. Liu, "Effects of steel fiber content and type on static mechanical properties of UHPCC," Construction and Building Materials, vol. 163, pp. 826-839, 2018.
[40] C. Shi, Z. Wu, D. Wang et al., "A review on ultra high performance concrete: raw materials and mixture design," Construction and Building Materials, vol. 101, pp. 1-13, 2015.

[41] H. Katrin, E. Denarié, and E. Brühwiler, "Experimental investigation of composite ultra-high-performance fiber-reinforced concrete and conventional concrete members," ACI Structural Journal, vol. 104, pp. 93-101, 2007.

[42] M. Daugevičius and J. Valivonis, "Concrete and reinforced concrete elements strengthened with HPFRCC," KSCE Journal of Civil Engineering, vol. 22, pp. 2961-2969, 2018.

[43] Z. Wu, C. Shi, Z. Wu, and D. Wang, "Uniaxial compression behavior of ultra-high performance concrete with hybrid steel fiber," Journal of Materials in Civil Engineering, vol. 17, pp. 1-7, 2016.

[44] S. Kwon, T. Nishiwaki, T. Kikuta et al., "Development of ultrahigh-performance hybrid finer-reinforced cement -based composites (with appendix)," ACI Materials Journal, vol. 111, no. 3, pp. 309-318, 2014.

[45] K. Kobayashi, Y. Asano, and K. Rokugo, "Application of HPFRCC as a patching repair material for RC members exposed to chloride attack," in Proceedings of the 2011 International Conference on Strain-Hardening Cement-Based Composites SHCC 2011: Strain-Hardening Cement-Based Composites, Rio de Janeiro, Brazil, December 2011.

[46] Q. Song, H. Zhao, J. Jia et al., "Pyrolysis of municipal solid waste with iron-based additives: a study on the kinetic, product distribution and catalytic mechanisms," Journal of Cleaner Production, vol. 258, Article ID 120682, 2020.

[47] A. Hemmati, A. Kheyroddin, M. Sharbatdar, Y. Park, and A. Abolmaali, "Ductile behavior of high performance fiber reinforced cementitious composite (HPFRCC) frames," Construction and Building Materials, vol. 115, pp. 681-689, 2016.

[48] L. Sharbatdar, S. Sun, J. Wang, W. Yang, S. Song, and Z. Fang, "Experimental study of the precursor information of the water inrush in shield tunnels due to the proximity of a water-filled cave," International Journal of Rock Mechanics and Mining Sciences, vol. 130, Article ID 104320, 2020.

[49] M. Schmidt and E. Fehling, "Ultra high performance concrete research development and application in Europe," in Proceedings of the 7th International Symposium on the Utilization of High Strength/High Performance Concrete, Washington, DC, USA, June 2005.

[50] M. Rouse Jon and L. Billington Sarah, "Creep and shrinkage of high-performance fiber-reinforced cementitious composites," ACI Materials Journal, vol. 104, no. 2, pp. 129-136, 2007.

[51] N. T. Tran, T. K. Tran, and D. J. Kim, "High rate response of ultra-high-performance fiber-reinforced concretes under direct tension," Cement and Concrete Research, vol. 69, pp. 72-87, 2015.

[52] J. Kim, X. Guo, and Y. Zhu, "Repeated penetration of ultrahigh performance concrete," in Proceedings of the 2014 International Conference on Strain-Hardening Cement-Based Composites SHCC 2014: Strain-Hardening Cement-Based Composites, Dordrecht, Netherlands, November 2014.

[53] J. Zhang and Y. Zhao, "The mechanical properties and microstructure of ultra-high-performance concrete containing various supplementary cementitious materials," Journal Sustainable Cement-Based Materials, vol. 6, no. 4, pp. 254266, 2017.

[54] D. Wang, C. Shi, Z. Wu, J. Xiao, Z. Huang, and Z. Fang, "A review on ultra high performance concrete: part II. Hydration, microstructure and properties," Construction and Building Materials, vol. 96, pp. 368-377, 2015. 
[55] K. Huang, H. Bian, W. Prince-Agbodjan, and B. Raghavan, "Effect of different types of fibers on the microstructure and the mechanical behavior of ultra-high performance fiberreinforced concretes," Composites Part B: Engineering, vol. 86, pp. 214-220, 2016.

[56] R. Sovják, P. Máca, and T. Imlauf, "Effect of fibre aspect ratio and fibre volume fraction on the effective fracture energy of ultra-high-performance fibre-reinforced concrete," Acta Polytechnica, vol. 56, no. 4, pp. 319-327, 2016.

[57] D.-L. Nguyen, M. N.-T. Lam, D.-J. Kim, and J. Song, "Direct tensile self-sensing and fracture energy of steel-fber-reinforced concretes," Composites Part B: Engineering, vol. 183, Article ID 107714, 2020.

[58] Tran, "Determination of the fracture energy of mortar and concrete by means of three-point bend tests on notched beams," Materials and Structures, vol. 18, pp. 285-290, 1985.

[59] National Development and Reform Commission of the People's Republic of China, Norm for Fracture Test of Hydraulic Concrete: DL/T 5332-2005, China Electric Power Press, Beijing, China, 2005.

[60] H. Yokota, K. Rokugo, and N. Sakata, JSCE Recommendations for Design and Construction of High Performance Fiber Reinforced Cement Composites with Multiple Fine Cracks (HPFRCC), JSCE, Tokyo, Japan, 1996.

[61] K. Yu, L. Li, J. Yu, Y. Wang, J. Ye, and Q. Xu, "Direct tensile properties of engineered cementitious composites: a review," Construction and Building Materials, vol. 165, pp. 346-362, 2018.

[62] China National Standards, Method of Testing Cements-Determination of Strength, GB/T 17671-2005, China National Standards, Beijing, China, 2005.

[63] E. Wang and F. H. Wittmann, "The Wedge splitting test, a new method of performing stable fracture mechanics tests," Engineering Fracture Mechanics, vol. 35, no. 1-3, pp. 117-125, 1990.

[64] Ł. Skarżyński and J. Tejchman, "Calculations of fracture process zones on meso-scale in notched concrete beams subjected to three-point bending," European Journal of Mechanics-A/Solids, vol. 29, no. 4, pp. 746-760, 2010.

[65] RILEM-Draft-Recommendation (50-FCM), "Determination of the structure energy of mortar and concrete by means of three-point bend test on notched beams," Materials and Structures, vol. 18, pp. 285-290, 1985.

[66] A. Hillerborg, "Results of three comparative test series for determining the fracture energy of concrete," Materials and Structures, vol. 18, no. 107, 1985.

[67] A. Hillerborg, "The theoretical basis of a method to determine the fracture energy GF of concrete," Materials and Structures, vol. 18, no. 4, pp. 291-296, 1985. 